\title{
Currículo e ensino de línguas adicionais: revisitando conceitos e pensando possibilidades
}

\author{
Cláudia Helena Dutra da Silva \\ UFRGS / IFSul
}

\begin{abstract}
Resumo
O objetivo deste trabalho é discutir o currículo escolar e seus objetivos. Além disso, busca refletir sobre a organização do currículo de línguas adicionais e o espaço para o trabalho com a pedagogia de projetos e gêneros do discurso.

Palavras-chave: ensino de línguas adicionais, currículo, pedagogia de projetos, gêneros do discurso
\end{abstract}

\begin{abstract}
This paper discusses the school curriculum and its purposes. It also focuses on reflecting about the organization of the additional language curriculum and the space for working with project pedagogy and speech genres.

Keywords: additional language teaching, curriculum, project pedagogy, speech genres
\end{abstract}

\section{INTRODUÇÃO}

Começo a discussão sobre currículo e controle na vida escolar com uma pergunta que tenho escutado já há algum tempo tanto de diversos pesquisadores sobre ensino e aprendizagem de línguas adicionais ${ }^{1}$ em escolas públicas quanto de colegas: Para quem as escolas funcionam? Esta não é uma pergunta simples e acredito que talvez seja por sua complexidade que a escuto com frequência nos últimos anos. Apple (2006), conhecido pesquisador na área de currículo, também discute tal questão algumas vezes e é a partir de algumas de suas considerações que encaminho a discussão sobre currículo e tento refletir sobre o assunto neste artigo.

\footnotetext{
${ }^{1} \mathrm{O}$ termo línguas adicionais é usado aqui no sentido proposto nos Referenciais do Estado do Rio Grande do Sul (RIO GRANDE DO SUL, 2009), considerando que as línguas estudadas na escola sejam um acréscimo ao repertório do aluno, e considerando também que, na sociedade atual onde há pessoas de diversas formações socioculturais e nacionalidades, torna-se difícil identificar quem seriam nativos e estrangeiros.
} 
Como pesquisadora e professora de línguas adicionais, sempre me questiono por que grande parte das escolas organiza seus currículos de forma tão semelhante. Tratando mais especificamente dos currículos de línguas adicionais, tema que tem sido bastante debatido por professores de diversas línguas, sobretudo de inglês, percebe-se que boa parte das escolas, em especial as escolas públicas, adota uma mesma visão de currículo, uma visão conteudista. Os currículos, em sua maioria, apresentam itens lexicais e conteúdos gramaticais que devem ser ensinados em cada série da Educação Básica. Algumas propostas (Rio Grande Do Sul, 2009; Schlatter, 2009; Silva, 2008; Santos, 2008; Andrighetti, 2006; Prado, 2006) já foram feitas buscando repensar a organização curricular e o ensino de línguas adicionais em escolas regulares, mas, na prática, pouco tem sido feito. Dessa forma, outra pergunta que inquieta professores de línguas é: Por que, apesar de estudos e propostas já terem sido pensados, as escolas continuam ensinando línguas da mesma forma?

A partir dessas inquietações, busco neste artigo refletir sobre essas perguntas e sobre algumas de suas possíveis respostas, investigando um pouco mais sobre questões sociais e ideológicas que se encontram por trás da organização do currículo escolar e da história do currículo. Apresento também um pouco do que vem sendo discutido sobre currículo de línguas adicionais e de algumas propostas mais recentes para o ensino de línguas em escolas.

\section{CURRÍCULO E CONTROLE SOCIAL}

Apple (2006) aponta que as escolas contribuem para desigualdades por serem organizadas de forma a distribuir diferentemente determinados tipos de conhecimento. De acordo com ele, as escolas desempenham boa parte da distribuição dos tipos de elementos normativos e das propensões exigidas, fazendo com que essa desigualdade pareça algo natural. Seus currículos parecem estar voltados para a manutenção da hegemonia ideológica das classes mais poderosas da sociedade, que, em parte, depende de nossa internalização dos princípios e das regras do senso comum que governam a ordem social existente.

$\mathrm{Na}$ escola moderna, uma das grandes questões levantadas por diversos professores e pesquisadores, que também é queixa dos alunos, é a falta de conexão entre a escola e a vida cotidiana dos alunos e o contexto das comunidades em que vivem. Esse mesmo fenômeno é observado por Apple (2006:83), que comenta sobre "a falta de 
atenção dispensada à relação entre conhecimento escolar e fenômenos extra-escolares". O autor argumenta que assim como há distribuição desigual de capital econômico, também há distribuição desigual de capital cultural, por isso há essa desatenção quanto à união desses dois conhecimentos.

Essa desigualdade leva o autor a questionar "de quem são os significados coletados e distribuídos por meio dos currículos nas escolas?” (Apple, 2006:84). Para Apple, historicamente o interesse pelos significados nas escolas está ligado a noções variadas de controle social. Como ele explica, a educação e os significados do currículo escolar eram vistos como elementos essenciais para preservar privilégios interesses e conhecimentos sociais que eram prerrogativas de uma parcela da população que se mantinha às custas de grupos com menos poder. Essa situação passada ainda pode ser identificada na escola moderna se pensarmos em como ela está estruturada, na falta de relação com fenômenos extraescolares de famílias de menor poder aquisitivo, as quais, em grande parte, não encontram suas culturas e problemas retratados nas escolas. Em função disso, decorre o problema apontado por Sacristán (2000:30): "quando os interesses dos alunos não encontram algum reflexo na cultura escolar, se mostram refratários a esta sob múltiplas reações possíveis: recusa, confronto, desmotivação, fuga, etc".

Outro ponto interessante referente à questão de desigualdade é que além da desigualdade da distribuição de capital cultural, há a desigualdade da distribuição social de conhecimento em salas de aula. Apple (2006) aponta que tipos diferentes de alunos obtêm diferentes tipos de conhecimento, o que está relacionado ao processo de rotulação social que ocorre nas escolas. É relativamente comum ouvir professores dizendo que tais alunos são muito "fraquinhos", que não podem ensinar as mesmas coisas que ensinam para outros alunos porque eles não acompanhariam, ou porque eles não vão ter oportunidades de aproveitar e usar esse conhecimento no futuro. Mas realmente cabe ao professor tomar esse tipo de decisão, privar o aluno de determinado conhecimento ou determinar o que lhe será útil ou não, embasado muitas vezes em rótulos sociais? Ainda cabe perguntar, como propõe Apple (2006:89), “o que acontece quando o conhecimento é filtrado por meio dos professores?".

Os alunos, além de muitas vezes não encontrarem suas culturas nas salas de aula e terem seu conhecimento filtrado, ainda precisam aprender a fazer parte deste processo escolar no qual devem se tornar competentes no que Apple (2006) chama de regras, normas, valores e inclinações necessárias para que atuem na vida institucional da 
sociedade atual. Segundo Sacristán (2000), notam-se entre nós confrontos de movimentos de opinião: alguns, por um lado, criticam os programas calcados mais unicamente em conhecimentos relativos a áreas disciplinares, enquanto de outro lado há reações contra pretensões de uma educação que dê menos importância a esses conhecimentos clássicos e mais às necessidades psicológicas e sociais dos indivíduos. Isso nos faz voltar à pergunta inicial sobre para quem as escolas funcionam, visto que são escolhidas normas para atuação na sociedade e que essas normas quase nunca são escolhidas a partir da realidade de comunidades menos privilegiadas, as quais continuam sem ver seu conhecimento dentro da escola.

Essa situação, segundo Apple (2006:96), se deve ao fato de que "o conteúdo formal do conhecimento curricular é dominado por uma ideologia do consenso", pois os conflitos, tanto intelectuais quanto normativos, não são bem vistos na vida social. $O$ autor problematiza que dessa forma as escolas parecem agir com certa conivência na ampliação de uma ordem social desigual e estratificada, na qual os professores acabam, muitas vezes, tão encapsulados quanto os alunos. Desse modo, "isolar a experiência escolar da complexa totalidade de que é parte constitutiva resulta em uma análise um pouco limitada demais" (Apple, 2006:97-98).

Esse isolamento contradiz a visão expressa por Sacristán (2000, p.90-92) de que o currículo “é um objeto social e histórico não apenas porque é a expressão de necessidades sociais, mas também porque se desenvolve através de mediatizações sociais, e as condições escolares são uma parte importante delas". Portanto, precisamos lembrar que as funções da educação escolarizada vão além daquilo expresso nos currículos e que os processos de aprendizagem dependem tanto dos fatores internos escolares quanto dos externos, aqueles que fazem parte da vida dos alunos.

Para tanto, de acordo com Machado (2010), é necessário que conheçamos os interesses, necessidades e demandas dos alunos; que incorporemos essas aspirações e expectativas a nossa atividade pedagógica; que os ajudemos a desenvolver suas capacidades de pensar, sentir e agir; que valorizemos a compreensão dos determinantes sociais, econômicos e políticos da realidade em que vivem, além da discussão de alternativas para a construção da vida. 


\section{O CURRÍCULO OCULTO}

Apple (2006) firma que o currículo oculto, o ensino tácito de normas e expectativas sociais e econômicas aos alunos não é tão oculto ou ingênuo e que as escolas estavam em parte projetadas para ensinar exatamente isso. $\mathrm{O}$ autor se refere a ele como uma variedade de preocupações sobre a padronização dos ambientes educacionais, sobre o ensino de valores morais e normativos e sobre o funcionalismo econômico. Ainda chama a atenção para o fato de que o currículo oculto não era em absoluto oculto, mas sim uma função aberta das escolas durante um bom tempo (Apple, 2006).

O autor aponta ainda que, ao crescerem, os alunos passam a questionar com alguma facilidade essas normas e essa padronização proposta pela escola e que, então, é necessária uma justificação contínua para que eles aceitem as distinções e regras sociais anteriormente aprendidas. Para isso, é preciso que as regras do senso comum sejam vistas como neutras e basicamente imutáveis, cabendo ao currículo enfatizar essas afirmações hegemônicas, ignorando o funcionamento do poder na vida cultural e social (Apple, 2006).

Como parte desse currículo oculto, dessas normas e valores que os professores não falam nas declarações de suas metas e objetivos, estão os modos pelos quais os alunos aprendem a lidar com esse sistema: salas de aula cheias, elogios, poder, o professor como primeiro "chefe", o falseamento de certos aspectos de seus comportamentos para conformarem-se ao sistema de recompensas existentes na maior parte das salas de aula (Apple, 2006).

Frente a essa situação e mentalidade didática, Sacristán (2000:90) defende que não se pode restringir a aprendizagem ao que se esgota em matérias, que é preciso manter uma "visão mais ecológica" do ambiente escolar como fonte de aquisições, buscando proporcionar ao aluno uma aprendizagem muito mais ampla, além dos sistemas simbólicos ou componentes intelectuais.

Como contraproposta a essa metodologia que não conseguia mais unir os interesses dos alunos à pedagogia escolar de forma muito satisfatória e acabava muitas vezes interferindo de forma negativa no processo de ensino e aprendizagem, surgiu a pedagogia de projetos, buscando reorganizar o currículo escolar e criar um novo vínculo entre a escola, os alunos e seus interesses. 


\section{PEDAGOGIA DE PROJETOS}

Há alguns anos, várias discussões sobre a organização do currículo escolar têm ocorrido, com o intuito de propor possibilidades para melhorar e mudar o trabalho desenvolvido nas escolas. Com a ideia de organizar o currículo de forma alternativa que não seja pela lista de conteúdos gramaticais e itens lexicais - e de aproximar a escola das práticas sociais dos alunos surgiu o trabalho com Pedagogia de Projetos.

A Pedagogia de Projetos muda o centro do objeto de estudo do conteúdo proposto pelo currículo ou professor para o indivíduo. Em função disso, há a necessidade de rever os papéis dos participantes: o professor precisa mudar seu papel tradicional de possuidor de um conhecimento que deve transmitir a outra pessoa; passando a se ver como um orientador, assessor, facilitador de oportunidades; já o aluno precisa deixar de lado o papel tradicional de passividade na aula para tornar-se coautor de sua aprendizagem.

O quadro abaixo indica as diferenças existentes entre currículos de um ensino tradicional, baseado em disciplinas e um ensino potencialmente transgressor, transdisciplinar, conforme apontado por Hernandez (1998:31):

Quadro 1: Diferenças entre o currículo disciplinar e o transdisciplinar

\begin{tabular}{|c|c|}
\hline Disciplinar & Transdisciplinar \\
\hline Centrado nas matérias & $\begin{array}{ll}\text { Centrado em } & \text { problemas } \\
\text { transdiciplinares } & \end{array}$ \\
\hline Conceitos disciplinares & Temas ou problemas \\
\hline Objetivos e metas curriculares & Perguntas, pesquisa \\
\hline $\begin{array}{lll}\text { Conhecimento } & \text { canônico } & \text { ou } \\
\text { estandardizado } & & \end{array}$ & Conhecimento construído \\
\hline $\begin{array}{l}\text { Unidades centradas em conceitos } \\
\text { disciplinares }\end{array}$ & Centradas em temas ou problemas \\
\hline Lição - textos & Projetos - fontes diversas \\
\hline Estudo individual & $\begin{array}{l}\text { Grupos pequenos trabalham por } \\
\text { projetos }\end{array}$ \\
\hline Centrado na escola & $\begin{array}{l}\text { Centrado no mundo real e na } \\
\text { comunidade }\end{array}$ \\
\hline $\begin{array}{l}\text { Conhecimento tem sentido por si } \\
\text { mesmo }\end{array}$ & $\begin{array}{l}\text { Conhecimento em função da } \\
\text { pesquisa }\end{array}$ \\
\hline Avaliação mediante provas & Avaliação através de portfólios \\
\hline O professor como especialista & O professor como facilitador \\
\hline
\end{tabular}


Conforme o quadro, percebemos que o currículo transdisciplinar não está mais centrado em matérias como o tradicional currículo disciplinar; essa nova abordagem troca os conceitos disciplinares por temas ou problemas; ela parte de perguntas e objetivos de pesquisa em vez de metas curriculares; busca construir o conhecimento e não trabalhar meramente o conhecimento canônico; troca as aulas organizadas por lições por aulas organizadas por projetos de pesquisa; busca desenvolver trabalho em grupo ao invés de focar no trabalho individual; não centra as aulas apenas no universo da escola, mas busca abranger a comunidade dos alunos; a avaliação não é classificatória, mas diagnóstica; além disso, nessa nova proposta, o professor não o detentor do saber, ele constrói esse saber com os alunos

De acordo com Barbosa (2004:11), os projetos servem para aprender, para que sejam colocadas questões interessantes que devem ser respondidas paulatinamente. Eles pretendem fazer os alunos pensarem em temas importantes, refletirem e indagarem a atualidade, a vida fora da escola. Os projetos são elaborados e executados para aprender a estudar, a pesquisar, a procurar informações, a exercer a crítica, a duvidar, a argumentar, a opinar, a pensar. Para isso, a autora aponta que o trabalho com Pedagogia de Projetos deve apresentar cinco momentos decisivos, etapas que devem fazer parte de qualquer processo educativo: 1) a definição do problema, 2) o planejamento do trabalho, 3) a realização (coleta, organização e registro das informações), 4) produto final, 5) a avaliação (Barbosa, 2004:10).

Hernández (2004:6) salienta que não se deve esquecer que o trabalho com projetos não se limita a uma questão de ensino e aprendizagem. Eles não podem separar-se de um sistema social em processo de mudança que teriam os seguintes eixos: a) uma visão política (aprender a tomar decisões e assumir responsabilidades), b) uma visão educativa (a escola é parte de uma comunidade onde os indivíduos aprendem com os outros), c) uma visão curricular (um currículo integrado de base que é resultado de um diálogo permanente com a realidade e as mudanças sociais) e d) uma visão de conhecimento (que desperte o interesse em aprender dentro e fora da escola).

Dessa forma, podemos entender que a pedagogia de projetos apresenta uma proposta de currículo mais focada na vida dos estudantes, no que acontece fora da escola, oferecendo oportunidades para que a sala de aula não seja uma caixa fechada que não faz sentido para os alunos, mas que se relaciona com a vida e os interesses deles. Essa relação entre o que acontece na escola com a vida dos alunos é importante em todas as disciplinas escolares; no entanto, busco, a partir de agora, relacionar a 
pedagogia de projetos com o ensino de línguas adicionais mais especificamente por ser esta a disciplina com a qual venho trabalhando no contexto escolar e realizando pesquisas.

\section{REPENSANDO O CURRÍCULO PARA O ENSINO DE LÍNGUAS ADICIONAIS}

O currículo de línguas adicionais nas escolas é, em geral, baseado no ensino descontextualizado de estruturas gramaticais e de vocabulário, tendo como foco $\mathrm{o}$ treinamento de habilidades linguísticas, raramente trabalhando-se com textos. Mesmo quando se realizam trabalhos com textos, o texto é, na maioria das vezes, utilizado como pretexto para trabalhar aspectos linguísticos, privilegiando-se a tradução, exercícios de completar lacunas com as estruturas estudadas e a pronúncia. A visão de língua subjacente a essas aulas é a de língua como

um conjunto de regras e o papel do professor é fazer com que os alunos a pratiquem e aprendam dentro da caixa fechada da sala de aula, isolada do contexto social maior e das práticas de linguagem para a ação social (SCHLATTER \& GARCEZ, 2001:2).

Essa visão de língua e do papel do professor, que predominantemente se percebe na escola, vai fortemente de encontro às razões educacionais mencionadas nos PCN para se aprender e ensinar uma língua adicional na escola pública: "fazer uso da linguagem para agir no mundo social" (PCN, 1998:38).

De acordo com Schlatter (2009:12), “entende-se que o ensino de língua estrangeira (doravante LE) a escola deve focalizar atividades que promovam o letramento, ou seja, a participação em diferentes práticas sociais que envolvem a leitura e a escrita na língua materna e na LE”. Desse modo, entendo que não basta o ensino de regras gramaticais e vocabulário. Isso não quer dizer que o ensino desse conhecimento sistêmico não faça parte do processo de ensino e aprendizagem de uma língua adicional; a questão é que o ensino da língua adicional não pode ser baseado apenas nisso. A relevância desse conhecimento está no que se pode fazer a partir dele. Seu ensino deve fazer parte de um processo que crie:

condições para que o educando possa [praticá-lo] de forma integrada a partir de temas relevantes ao seu contexto e de gêneros discursivos variados. [...] Em última análise, aprender a ler e escrever (e também ouvir e falar) em determinadas situações de comunicação da LE tem como meta ampliar a participação do educando nas práticas sociais em sua língua e em sua cultura, contribuindo para desenvolver a cidadania (Schlatter, 2009:12). 
Percebe-se que o valor da disciplina de língua adicional não está apenas na aprendizagem das habilidades linguísticas ou na capacidade do educando de comunicarse através dessa língua, mas nas contribuições que o conhecimento dessa língua pode proporcionar à compreensão de mundo por parte desse educando cidadão. As Orientações Curriculares para o Ensino Médio (OCEM) sugerem que, em vez de se ensinar os conteúdos escolares voltados para si próprios, os conteúdos escolares sejam ensinados de forma a expandir a compreensão de mundo, relacionando esses conteúdos com a sociedade e a vida dos educandos. Desse modo, espera-se que haja uma maior “compreensão da complexidade social em que vivem os cidadãos", entendendo-se que a “diversidade [é] um dos componentes dessa complexidade” (BRASIL, 2006:94).

Assim, nos últimos anos, o ensino de línguas adicionais em escolas tem sido repensado, buscando embasá-lo em noções de letramento, entendido como "estado ou condição de quem não só sabe ler e escrever, mas exerce as práticas sociais de leitura e de escrita que circulam na sociedade em que vive, conjugando-as com as práticas sociais de interação oral" (Soares, 1999:3 apud Bagno \& Rangel, 2005:69). Além do conceito de letramento, outra concepção importante para o ensino e o currículo de línguas é a noção de gênero discursivo proposta por Bakhtin (2003:262): “cada campo de utilização da língua elabora seus tipos relativamente estáveis de enunciados, os quais denominamos gêneros do discurso".

A discussão sobre o ensino baseado nesses dois conceitos surgiu principalmente em função de que, embora as práticas de letramento tenham sido pauta de discussões sobre o ensino de língua materna, pouco se discute essas noções em relação ao ensino de língua adicional. Moraes \& Kleiman (1999:115) defendem a leitura em diferentes áreas, apresentando propostas para práticas de letramento em diversas disciplinas a partir do uso de notícias e reportagens, mas, quando tratam do ensino de língua adicional, não explicitam como isso poderia ser feito através de exemplos práticos. Limitam-se a levantar a necessidade de organizar o ensino para a leitura de diferentes gêneros discursivos. Entretanto, vale mencionar que, embora em número menor, há pesquisadores preocupados com estudos de gêneros discursivos no ensino de línguas adicionais (ver Cristóvao, 2002; Lima, 2008; Schlatter, 2009; Silva, 2008).

Uma forma encontrada para colocar em prática o ensino de línguas embasado nesses dois conceitos é trabalhar com o currículo organizado a partir da proposta da pedagogia de projetos. Nesse caso, os gêneros são os usos que fazemos da língua, ou 
seja, a língua em ação, sendo usada em contextos reais, não as regras abstratas e facilmente esquecidas; e os projetos são as formas, os contextos em que esses usos da língua ocorrem. Assim, a partir dessa proposta de organização curricular, é possível aproximar a escola das práticas sociais dos alunos.

Os Referenciais do Estado do Rio Grande do Sul (RIO GRANDE DO SUL, 2009), a meu ver, são uma interessante proposta de organizar o currículo de línguas adicionais tanto para o ensino fundamental quanto para o médio. $\mathrm{O}$ documento propõe um currículo organizado por temas geradores que buscam ser relevantes para a faixa etária das séries. A ideia é pensar nos temas que estão em foco na vida dos estudantes de acordo com suas idades e, a partir desses temas, pensar quais gêneros discursivos são usados em contextos reais para abordar esses assuntos. Os temas e os gêneros são conectados com as propostas de projetos em que os alunos discutirão essas temáticas e trabalharão com os gêneros propostos preparando para uma produção final que resultará de todo o trabalho realizado durante o projeto. Os conteúdos de gramática e de vocabulário continuam presentes nas aulas, porém, não são a estrutura do currículo. Esses itens estão a serviço dos projetos, sendo estudados à medida que são necessários. Estudam-se estruturas e itens lexicais que são relevantes para o trabalho com determinado gênero e importantes para a compreensão dos textos estudados naquele momento.

Com essa proposta, os alunos podem, então, passar a tratar de questões que são relevantes dentro de sua comunidade, levando seus problemas, sua cultura, necessidades, interesses para dentro da sala de aula. Uma proposta de trabalho como essa pode apresentar chances maiores de envolver os alunos do que uma proposta de currículo baseada em conteúdos gramaticais. No entanto, essa proposta também demanda mais planejamento do professor, mais tempo para organizar e pensar esses materiais, assim como abertura para as questões que ele não pensou e que podem surgir em sala de aula.

Talvez essas sejam algumas das questões que fazem com que o currículo em grande parte das escolas continue sendo organizado da mesma forma, pensado para que os alunos não discutam aquilo que lhes é interessante e sim para trabalharem com noções abstratas que parecem bastante distantes de suas vidas e pouco prováveis de serem usadas fora da escola. Mudar a organização curricular atual pode significar dar mais voz aos alunos, mais espaço para exporem suas dúvidas e questionamentos, o que pode não ser necessariamente o que a escola deseja para seus alunos. Isso novamente 
nos faz questionar para quem funcionam as escolas. Se for para os alunos e suas comunidades, nada mais justo do que dar o devido espaço para que se pronunciem e se tornem indivíduos mais críticos, participativos e construtores dos seus saberes, sejam eles escolares ou não.

\section{CONSIDERAÇÕES FINAIS}

A pergunta inicial desse artigo continua em aberto para mim, assim como para vários pesquisadores especializados na área de estudos sobre currículos. Mas acredito que mais importante do que respondê-la é ter consciência de que essa é uma pergunta de grande relevância quando pensamos em educação escolarizada. E acredito que tão importante quanto estar atento a esta pergunta é nos questionarmos, como professores, para quem desejamos que as escolas funcionem.

Para isso, é necessário que, conforme Machado (2010) expõe, contemos com projetos pedagógicos como resultado de construções coletivas, um processo que deve superar a aplicação atual de pacotes previamente estabelecidos e ter tanto professores quanto alunos como sujeitos do processo de ensino-apredizagem. É uma questão de tomar informações do contexto e das práticas socializadas pelos alunos, sistematizá-las com a ajuda dos conhecimentos disponíveis e pensá-las para que possam se tornar alternativas de transformação da realidade.

Portanto, não podemos esquecer que a teoria do currículo jamais poderá ser construída unicamente sobre o estudo desses processos de ensino-aprendizagem; ela precisa sempre relacionar-se com o estudo dos valores desses processos em uma sociedade concreta. Afinal, “a educação transforma-se em reprodução, não por simples transmissão de conhecimento, habilidades ou atitudes, mas através da transformação dinâmica das estruturas econômicas, sociais e culturais da sociedade, através do contexto do ensino" (Lundgren, apud Sacristán, 2000:90).

\section{REFERÊNCIAS}

Andrighetti, G. H. (2006). Pedagogia de projetos: reflexão sobre a prática no ensino de português como L2. Trabalho de Conclusão de Curso de Graduação em Letras, UFRGS.

Apple, M. W. (2006). Ideologia e currículo. Porto Alegre: Artmed. 
Bagno, M. \& Rangel, E. O. (2005). Tarefas da educação lingüística no Brasil. Revista Brasileira de Linguística Aplicada, 5 (1), 63-81.

Bakhtin, M. (2003). Estética da Criação Verbal. São Paulo: Martins Fontes.

Barbosa, M. C. S. (2004). Por que voltamos a falar e a trabalhar com a Pedagogia de projetos? Projeto - Revista de Educação: Projetos de trabalho, 3 (4), 8-13.

BRASIL. (2006). Secretaria de Educação Básica. Orientações Curriculares para o Ensino Médio - Conhecimentos de línguas estrangeiras. Brasília: Ministério da Educação, Secretaria de Educação Básica.

BRASIL. (1998). Secretaria de Educação Fundamental. Parâmetros Curriculares Nacionais: terceiro e quarto ciclos do ensino fundamental: língua estrangeira. Brasília: Ministério da Educação, Secretaria de Educação Fundamental.

Cristóvão, V.L.L. (2002). Gêneros e ensino de leitura em LE: os modelos didáticos de gêneros na construção e avaliação de material didático. Tese de doutorado em Linguística Aplicada e Estudos da Linguagem, PUC/SP.

Hernández, F. (1998). Transgressão e mudança na educação: os projetos de trabalho. Porto Alegre: Artmed.

. (2004). Os projetos de trabalho: um mapa para navegantes em mares de incertezas. Projeto - Revista de Educação: Projetos de trabalho, 3 (4), 2-7.

Lima, M. S. (2008). Práticas de letramento no ensino de LE : uma proposta de ensino através do gênero discursivo letra de música. Trabalho de Conclusão de Curso de Graduação em Letras, UFRGS.

Machado, L. (2010). Ensino médio e técnico com currículos integrados: propostas de ação didática para uma relação não fantasiosa. In: Moll, J. et al (eds.). Educação profissional e tecnológica no Brasil contemporâneo. Porto Alegre: ArtMed.

Moraes, S. E. \& Kleiman, A. (1999). Leitura e interdisciplinaridade: tecendo redes nos projetos da escola. São Paulo: Mercado de Letras.

Prado, V. V. (2006). Inglês na educação de jovens e adultos (EJA): uma proposta de ensino com enfoque em leitura. Trabalho de Conclusão de Curso de Graduação em Letras, UFRGS.

RIO GRANDE DO SUL. (2009). Secretaria da Educação. Departamento Pedagógico. Referenciais curriculares do Estado do Rio Grande do Sul. Porto Alegre: Secretaria da Educação.

Sacristán, J. G. (2000). O currículo - uma reflexão sobre a prática. Porto Alegre: Artes Médicas.

Santos, F. P. (2008). "O inglês e eu": uma proposta de projeto de língua inglesa em EJA. Trabalho de Conclusão de Curso de Graduação em Letras, UFRGS. 
Schlatter, M. (2009). O ensino de leitura em língua estrangeira na escola: uma proposta de letramento. Revista Calidoscópio, 7 (1), 11-23.

Schlatter, M. \& Garcez, P. M. (2001). Treinamento ou educação no ensino de língua: escolha metodológica ou política. In: Anais do VI Congresso Brasileiro de Lingüística Aplicada - A linguagem como prática social.

Silva, C.H.D. (2008). Uma proposta de letramento para o ensino de língua estrangeira na escola pública. Trabalho de Conclusão de Curso de Graduação em Letras, UFRGS.

\section{A AUTORA}

Cláudia Helena Dutra da Silva é professora de língua inglesa do Instituto Federal SulRio-Grandense (IFSUL), no Campus Venâncio Aires e é Mestre em Linguística Aplicada pela Universidade Federal do Rio Grande do Sul (UFRGS).

E-mail: claudia.helena@ufrgs.br 